\title{
Metal Release of Standard and Fake Orthodontic Braces: An In Vitro Study
}

\author{
Siti Hajjar N, Muhammad Syahmi MA, Muhammad Muaz AM \\ Kulliyyah of Dentistry, International Islamic University Malaysia, Pahang, Malaysia.
}

\section{ABSTRACT}

INTRODUCTION: The growing demand for orthodontic braces among Malaysians has led to the development of fake braces. These fake braces services are illegal and their brackets are reported to be of inferior quality. Fake braces are constantly being exposed to the saliva intraorally, hence they are susceptible to corrosion. This study was conducted to investigate the release of metal ions as a result of corrosion from standard and fake orthodontic braces immersed in artificial saliva of different $\mathrm{pH}$. MATERIALS AND METHODS: A total of six different types of brackets (three from standard and three from fake braces) were immersed in containers containing $5 \mathrm{~mL}$ of artificial saliva of $\mathrm{pH} 4.9$ and $\mathrm{pH}$ 7.8. The samples were collected for analysis on day 1, day 14, and day 28 using Inductively-Coupled Plasma Mass Spectrometry (ICPMS) to evaluate the amount of metal ion released. Statistical analysis was performed to isolate the significant difference of metal ions released between two types of braces in different pH solutions. RESULTS: The release of aluminum, nickel, chromium, manganese and copper were observed and analyzed. Fake braces released the highest concentration of chromium, manganese, and nickel ions in both artificial saliva as compared to standard braces. Brackets immersed in $\mathrm{pH} 4.9$ released a higher number of ions compared to $\mathrm{pH}$ 7.8. CONCLUSION: This study showed that fake braces released the highest concentration of metal ions as compared to standard braces. Both time and $\mathrm{pH}$ influenced the release of metal ions from orthodontic brackets.

KEYWORDS: Orthodontic bracket, Braces, Spectrometry, Corrosion

\section{INTRODUCTION}

The purpose of orthodontic treatment is to correct dental malocclusion, management of skeletal discrepancies and craniofacial deformity. This treatment which once thought to cause discomfort and insecurity is now being perceived as fashion accessories especially among the Asian teenagers. Orthodontic treatment is thought to symbolize someone's wealth, status, and lifestyle because the treatment is expensive. This

\section{Corresponding Author:}

Dr. Siti Hajjar Nasir Department of Orthodontics,

Kulliyyah of Dentistry,

International Islamic University Malaysia,

Jalan Sultan Ahmad Shah, Bandar Indera Mahkota,

25200 Kuantan Pahang, Malaysia.

Tel No: $+609-5705505$

Email : drhajjar@iium.edu.my growing demand for orthodontic braces among Malaysian community has led to the development of fake braces. Nowadays, many fake and braces services are being offered through social media by unqualified personnel using poor quality orthodontic brackets. ${ }^{1}$ The fake braces are not bonded onto teeth and are unable to produce tooth movement. Fake braces services are provided by individual with no formal dental education in unlicensed premises. On the contrary, standard braces are brackets used by certified orthodontic specialists and these brackets are manufactured by medical device manufacturers.

Orthodontic brackets are manufactured from different types of alloys and they contain protective oxide layer that protect the alloy surface from corrosion. ${ }^{2}$ Corrosion of the orthodontic brackets develop when brackets are 
in direct contact with saliva, which acts as an electrolyte in the oral cavity. The oral cavity environment that favour the corrosion process are reported to be contributed by diet rich in sodium chloride, acidic carbonated drinks and fluoride-containing products such as toothpaste and mouthwash. ${ }^{3}$ The dissolution of this oxide layer (passivation) exposes the metal surface and causes the release of metal ions such as nickel, chromium and cobalt, which has been reported to cause hypersensitivity, dermatitis, and asthma ${ }^{4-6}$. Metal ion release was believed to be influenced by the composition of the metal and not the content of metal in an appliance. ${ }^{7}$ Previous studies reported that the preexisted surface defects and irregular bracket surfaces are more susceptible to corrosion. ${ }^{1,8,9}$

Studies that investigated the biocompatibility of standard orthodontic brackets have been well documented. However, studies that explore the corrosion of fake braces has never been conducted. Therefore, the aim of this study was to investigate the release of metal ions in artificial saliva from standard and fake orthodontic brackets. Furthermore, the effects of $\mathrm{pH}$ and time of exposure on the release of metal ions from these brackets were also evaluated.

\section{MATERIALS AND METHODS}

\section{Samples}

This study utilizes orthodontic brackets sampled from a previous study. ${ }^{1}$ The sample consist of six orthodontic brackets (Figure 1) and the details of each bracket are as follows: Fake braces 1 to fake braces 3 has no brands; Standard braces 1-3M Victory Series ${ }^{\text {TM }}$ from 3M Unitek; Standard braces 2-Forestadent Quick ${ }^{\circledR}$ from Forestadent; Standard braces 3-MEM Dental EPS from MEM Dental Technology. Samples for fake braces were sourced from multiple online suppliers. Two different types of artificial saliva: Fusayama/Meyer ( $\mathrm{pH} 4.9$ ) and AFNOR NF S91-141 (pH 7.8) were used in this study. The chemical composition of Fusayama/Meyer ( $\mathrm{pH} 4.9)$ artificial saliva is described as follows: $97-100 \%$ water, distilled water, deionized water, $<0.1 \%$ Potassium Chloride, $<0.5 \%$ Urea, $<0.1 \%$ Sodium Chloride, $<0.1 \%$ Sodium Phosphate Monobasic
Dihydrate, $\quad<0.1 \%$ Calcium Chloride Dihydrate, $<0.0005 \%$ Sodium Sulfide Nonahydrate; whereas the composition of AFNOR NF S91-141 ( $\mathrm{pH} 7.8$ ) artificial saliva is described as follows: $0.7 \mathrm{~g} / 1 \mathrm{NaCl}, 1.2 \mathrm{~g} / 1 \mathrm{KCl}$, $0.26 \mathrm{~g} / 1 \mathrm{Na}_{2} \mathrm{HPO}_{4} \mathrm{H}_{2} \mathrm{O}, 1.5 \mathrm{~g} / 1 \mathrm{NaHCO}_{3}, 0.33 \mathrm{~g} / 1$ $\mathrm{KSCN}$ and $1.35 \mathrm{~g} / 1$ urea, 60-70\% Nitric Acid (TraceMetal ${ }^{\mathrm{TM}}$ Grade), Deionized water, 2\% Nitric Acid.

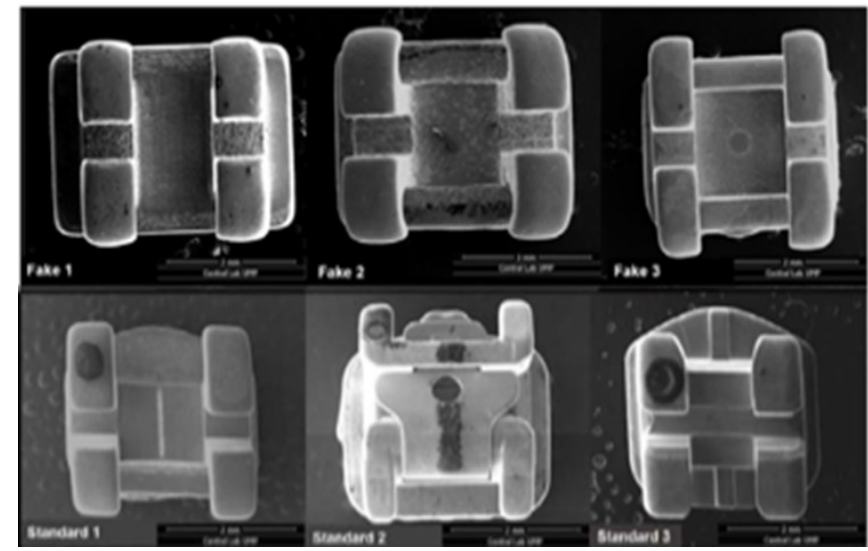

Figure 1 Top left to right: Three types of fake braces, all fake braces has no brands. Bottom left to right: Standard braces 1-3M Victory Series ${ }^{\mathrm{TM}}$; Standard braces 2-Forestadent Quick ${ }^{\circledR}$; Standard braces 3- MEM Dental EPS.

\section{Sample preparation}

Containers containing $5 \mathrm{ml}$ of artificial saliva of $\mathrm{pH} 4.9$ and 7.8 were prepared. All six brackets were then immersed in these containers containing artificial saliva. Three different time-frames (Day 1, Day 14 and Day 28) were selected to evaluate the effect of corrosion of standard and fake orthodontic brackets. The solutions were then incubated according to the designated timeframe in a Memmert water bath WNB $7-45$ at $37.0^{\circ} \mathrm{C}$.

\section{Sample digestion}

The artificial saliva solution was first digested in order to determine the level of metal ions. $1 \mathrm{ml}$ of artificial saliva solution and $1 \mathrm{ml}$ of $67 \%$ nitric acid (TraceMetal ${ }^{\mathrm{TM}}$ Grade) were pipetted into the Teflon vessels. Then, Teflon bombs were placed in an oven of $100.0^{\circ} \mathrm{C}$ for 1 hour and later cooled for another 1 hour. The mixed solution in Teflon bombs were transferred into individual centrifuge tubes and further diluted with deionized water until the solutions reach the volume of $10 \mathrm{ml}$. 


\section{Instrumental analysis}

The digested solution was then analysed for metal content using an Inductively-Coupled Plasma Mass Spectrometry ICPMS (Perkin Elmer ICPMS Elan 9000). Interferences were eliminated using internal standards and ionization buffers. Instrument machine calibration was done using calibration solution (PerkinElmer Multielement Calibration Standard 3) to achieve accurate element detection and concentration analysis. QC sample standard was also performed using QCP-QCS-3 solution (Inorganic Ventures) to ensure the accuracy of the analysed elements and concentration. All the analytical procedures were performed under the EPA method 200.7.

\section{Statistical analysis}

Statistical analysis was performed using the SPSS version 23.0 (SPSS Inc., Chicago, USA). Kruskal-Wallis test was used to isolate significant difference of metal ions release between standard and fake braces in artificial saliva after 28 days. The test was also used to determine the significant difference of metal ions release between braces in different $\mathrm{pH}$ solutions. Statistical significance was determined when $\mathrm{P}<0.05$.

\section{RESULTS}

The average metal ion release $(\mathrm{ug} / \mathrm{L})$ from standard and fake brackets were presented in Table I ( $\mathrm{pH} 4.9)$ and Table II (pH 7.8). From the ICP-MS analysis, the following metal ions were selected due to their cytotoxic and allergenic properties: aluminium, nickel, chromium, manganese and copper. In general, the release of the metal ions was higher in $\mathrm{pH} 4.9$ compared to $\mathrm{pH}$ 7.8. Nickel showed the highest release of ions into the artificial saliva, followed by chromium and aluminium. Copper showed the lowest release rate as compared to other ions in both $\mathrm{pH} 4.9$ and 7.8.

When comparing between the two types of brackets, fake braces released the highest concentration of nickel in the first 14 days. After day 14, the release of the nickel ions decreased. This is in contrary with chromium and aluminium, which increased significantly after day 14 . The amount of chromium ion release was found to be highest on day 28 for all types of brackets. Aluminium ion release continued to increase significantly on day 28 with the fake braces again having the highest ion concentration. Copper ion release was generally low compared to other metal ions. The copper ion release in $\mathrm{pH} 4.9$ was low during day 14 and then increased for day 28 for most of the brackets.

Table III showed the results of Kruskal-Wallis $\mathrm{H}$ test used to analyse the types of bracket used and the exposure time on the release of ions between standard and fake orthodontic brackets. The test showed a statistically significant difference in the release of chromium ions $(\mathrm{P}=0.044)$ and manganese ions $(\mathrm{P}=$ 0.022 ) for day 1 . On the other hand, the release of nickel showed a statistically significant difference during day $14(\mathrm{P}=0.027)$.

The mean rank suggested that the release of these ions in fake braces is higher than standard braces. Table IV showed the results of Kruskal-Wallis $\mathrm{H}$ test used evaluate the release of metal ions between $\mathrm{pH} 4.9$ and $\mathrm{pH}$ 7.8. Statistically significant difference in the release

Table I: The average metal ion release by standard and fake bracket in artificial saliva with $\mathrm{pH}$ 4.9.

\begin{tabular}{lccccccccccc}
\hline \multicolumn{10}{c}{ Average Metal Ion Release, ug/L } \\
\hline \multirow{2}{*}{ Brackets } & Day & Mean & SD & Mean & SD & Mean & SD & Mean & SD & Mean & SD \\
Standard & 1 & 16.7 & 6.1 & 33.7 & 22.5 & 16.7 & 5.8 & 90.0 & 34.6 & 13.3 & 15.3 \\
& 14 & 96.7 & 124.2 & 340.0 & 415.8 & 30.0 & 20.0 & 1936.7 & 773.6 & 3.3 & 5.8 \\
& 28 & 1766.7 & 509.5 & 2470.0 & 350.3 & 140.0 & 144.2 & 333.3 & 141.9 & 46.7 & 56.9 \\
Fake & 1 & 133.3 & 105.0 & 43.3 & 6.7 & 50.3 & 36.6 & 1180.0 & 195.2 & 26.7 & 11.5 \\
& 14 & 176.7 & 187.2 & 410.0 & 435.9 & 6.67 & 11.5 & 8436.7 & 1622.8 & 10.0 & 10.0 \\
& 28 & 2933.3 & 1191.8 & 4716.7 & 2824.1 & 73.3 & 15.3 & 1110.0 & 630.9 & 20.0 & 10.0 \\
\hline
\end{tabular}


Table II: The average metal ion release by standard and fake bracket in artificial saliva with $\mathrm{pH}$ 7.8.

\begin{tabular}{|c|c|c|c|c|c|c|c|c|c|c|c|}
\hline \multirow[b]{3}{*}{ Brackets } & \multirow[b]{3}{*}{ Day } & \multicolumn{8}{|c|}{ Average Metal Ion Release, $\mu \mathrm{g} / \mathrm{L}$} & \multirow{2}{*}{\multicolumn{2}{|c|}{$\mathrm{Cu}$}} \\
\hline & & \multicolumn{2}{|c|}{ Al } & \multicolumn{2}{|c|}{$\mathrm{Cr}$} & \multicolumn{2}{|c|}{$\mathrm{Mn}$} & \multicolumn{2}{|c|}{$\mathbf{N i}$} & & \\
\hline & & Mean & SD & Mean & SD & Mean & SD & Mean & SD & Mean & SD \\
\hline \multirow[t]{3}{*}{ Standard } & 1 & 16.7 & 8.3 & 10.0 & 10.0 & 0.0 & 0.0 & 103.3 & 15.3 & 16.7 & 28.9 \\
\hline & 14 & 6.7 & 5.8 & 331.3 & 371.9 & 3.3 & 5.8 & 1736.7 & 55.1 & 46.7 & 14.5 \\
\hline & 28 & 396.7 & 213.6 & 2496.7 & 605.0 & 123.3 & 94.5 & 1746.7 & 723.4 & 40.0 & 20.0 \\
\hline \multirow[t]{3}{*}{ Fake } & 1 & 53.3 & 83.9 & 560.0 & 151.3 & 40.0 & 20.0 & 183.3 & 100.2 & 70.0 & 26.5 \\
\hline & 14 & 43.3 & 25.2 & 633.3 & 135.8 & 136.7 & 96.1 & 6490.0 & 290.0 & 46.7 & 41.6 \\
\hline & 28 & 3366.7 & 2624.1 & 3293.3 & 161.7 & 76.7 & 30.6 & 3240.0 & 1254.9 & 20.0 & 10.0 \\
\hline
\end{tabular}

of aluminum during day $14 \quad(\mathrm{P}=0.005)$ and for nickel during day $28 \quad(\mathrm{P}=0.002)$. The mean rank value suggested that the release of aluminum ions at day 14 was higher in $\mathrm{pH} 4.9$ whereas the release of nickel at day 28 was higher in $\mathrm{pH} 7.8$.

Table III: Kruskal-Wallis test on analysis of ions release between standard and fake brackets.

\begin{tabular}{ccccc}
\hline & $\begin{array}{c}\text { Type of } \\
\text { Bracket }\end{array}$ & N & Mean Rank & $\begin{array}{c}\text { P-value } \\
\text { (Kruskal - } \\
\text { Wallis H } \\
\text { test) }\end{array}$ \\
\hline Chromium & Standard & 3 & 2.83 & \\
(Day 1) & Fake & 3 & 8.00 & $0.044^{*}$ \\
& Total & 6 & & \\
Manganese & Standard & 3 & 3.50 & \\
(Day 1) & Fake & 3 & 8.00 & $0.022^{*}$ \\
Nickel & Total & 6 & & \\
(Day 14) & Standard & 3 & 2.00 & \\
\hline
\end{tabular}

\section{DISCUSSION}

The ion release from standard and fake orthodontic brackets immersed in artificial saliva were highlighted in this study. It was found that fake braces released the highest concentration of metal ions in artificial saliva as compared to standard orthodontic brackets. The release of the metal ions in this study is of a non-linear metal release which means that the ion released did not have a constant rate. This is in agreement with another study by Wendl et al that showed variable metal release profile and are most probably due to differing degrees of surface passivation of the tested components. ${ }^{8}$ The nickel ion released in this study is also a non- linear ion release. The value increased in the first 14 days and then decreased on day 28 as shown previously. However, the release of chromium and aluminium increased slightly between day 1 and day 14 and then the values increased significantly on day 28. Whereas for manganese and copper, the ion release decreased between day 1 and day 14 and then multiplied on day 28.

Table IV: Kruskal-Wallis test on analysis of ion release between pH 4.9 and $\mathrm{pH} 7.8$.

\begin{tabular}{ccccc}
\hline & $\mathrm{pH}$ & $\mathbf{N}$ & Mean Rank & $\begin{array}{c}\text { p-value } \\
\text { (Kruskal - } \\
\text { Wallis H } \\
\text { test) }\end{array}$ \\
$\begin{array}{c}\text { Aluminium } \\
\text { (Day 14) }\end{array}$ & 4.9 & 6 & 13.00 & \\
& 7.8 & 6 & 6.00 & $0.005^{*}$ \\
& Total & 12 & & \\
Nickel & 4.9 & 6 & 5.67 & $0.002^{*}$ \\
\hline (Day 28) & & & & \\
\hline
\end{tabular}

A variety of factors can affect the amount of metal released from orthodontic appliances including galvanic corrosion of different types of metals, the corrosion resistance of the material, brazing or welding effects on the metal and the surface texture of the appliance. According to the first part of this study, fake braces were observed to have unpolished surfaces with visible crack lines making it a favourable site for corrosion to develop. Defects and rough surfaces on orthodontic bracket generates disorganization to the crystal lattice of the metal bracket thus making the bonds between the atoms weak. This led to the formation of bonds with elements in the artificial saliva which causes the metal to discharge from the brackets. Hunt et al. conducted a study on the corrosion of orthodontic wires and concluded that polishing can significantly reduce the corrosion rate of nickel titanium. ${ }^{10}$ These results are also in agreement with another study that found brackets 
with surface roughness or defects treated in corrosive media will produce more severe and obvious defect as a result of corrosion. ${ }^{11}$

In this study, two different types of artificial saliva selected were Fusayama/Meyer ( $\mathrm{pH} 4.9)$ and AFNOR NF S91-141 (pH 7.8). The reason behind this was to mimic the $\mathrm{pH}$ of oral environment in both acidic (during meal) and neutral environment. The saliva $\mathrm{pH}$ is regulated by the bacteria in dental plaque and is able to stimulate the metal ions released from brackets into the saliva ${ }^{12}$. Oral food clearance and low $\mathrm{pH}$ drinks such as fruit juices, soft and carbonated drinks cause the reduction of $\mathrm{pH}$ in the oral cavity thus making it more acidic. Nickel titanium orthodontic alloys corrode and undergo degradation of their mechanical properties in an acidic environment. Brackets corrosion resistance is highly dependent on the formation of oxide film (passivation), which spontaneously forms and maintained by oxygen. ${ }^{13-15}$ However, the presence of acid and chloride ions can damage this protective oxide layer and therefore releasing the ions from brackets into the oral environment.

Metal corrosion is an electrochemical process in which a metal surface is exposed to a conducting aqueous electrolyte. This will usually become the site for two simultaneous chemical reaction which are oxidation and reduction, also known as 'redox' 14. In this study, aluminium ion release was the highest among all other metal ion released in acidic environment whereas nickel ion was the highest concentration of metal ion release in neutral environment. Lower $\mathrm{pH}$ artificial saliva has high concentration of hydrogen ion $\left(\mathrm{H}^{+}\right)$which in relation to the reactivity series was lower compared to aluminium and nickel. However, comparing aluminium and nickel in relation with hydrogen $(\mathrm{H})$, aluminium is more reactive than nickel. Therefore, chemical reactions between $\mathrm{H}$ and aluminium are more likely to happen thus resulting in higher concentration of aluminium ion in acidic environment. Nickel continue to corrode in acidic environment but is slower when compared to aluminium.

The corrosion of metal appliances is an important controversial issue in orthodontics. Corrosion releases metal ions into the oral cavity which later can be absorbed into the oral tissues locally or ingested into the gastrointestinal system and causes systemic adverse biological effects. ${ }^{16}$ Chromium and nickel ions are known to induce type IV hypersensitivity and orthodontic patients have been reported to have twofold more nickel allergy compared with non-orthodontic patients. ${ }^{5}$ The World Health Organization (WHO) has quantified the recommended dietary allowance and adequate intake (RDI) for the five elements that were investigated in this study. The RDI are listed below: nickel, < 1mg/day; Chromium, $35 \mu \mathrm{g} /$ day; Manganese, 1.9-11 mg/day; Copper, $900 \mu \mathrm{g} / \mathrm{day}$, whereas for the aluminium, the Joint FAO/WHO Expert Committee on Food Additives (JECFA) stated the value of $30 \mathrm{mg} /$ $\mathrm{kg} /$ day ${ }^{17}$. From the results obtained, the average value of nickel ions released from all the brackets exceed the recommended value of $1 \mathrm{mg} /$ day with the highest value recorded in the fake braces immersed in $\mathrm{pH} 4.9$ (1205.2 $\mu \mathrm{g} /$ day). No other elements have been found in this study to exceed the recommended daily dose (RDD). Thus, only nickel was found to pose a potential risk for hypersensitivity in patients with fake braces. This is in accordance with the results from a study which also found that nickel ion release has exceeded the RDD.?

The limitation of this in-vitro study is that it did not completely represent the dynamic of oral environment during eating and at rest. During mastication, salivary buffer system containing bicarbonates, peptides and phosphates play an important role in neutralising the acidic oral environment, thus reducing the concentration of metal ions released from orthodontic appliances. Therefore, the release of metal ions in this study can be considered to be greater than the actual release of ions in patients' oral cavity. However, orthodontic brackets are usually placed intraorally for more than a year and patients will experience a much longer exposure time to the corroded brackets.

\section{CONCLUSION}

This study showed that fake braces released the highest amount of nickel and chromium ions as compared to standard orthodontic brackets. Both parameters $(\mathrm{pH}$ $\&$ time) influenced the release of metal ions from orthodontic brackets. Metal ions release were significantly higher in lower $\mathrm{pH}$ and longer immersion time. The high level of ion released from fake braces may pose potential risk of toxicity and hypersensitivity 
to wearers. Further study on the effect of metal ions release from fake braces on the oral tissues and their biocompatibility need to be investigated.

\section{CONFLICT OF INTEREST}

The authors certify that there is no actual or potential conflict of interest in relation to this article.

\section{ACKNOWLEDGEMENTS}

We would like to acknowledge the assistance of $\mathrm{Mr}$. Abdul Halim bin Ihsan, Assistant Science Officer and Madam Fatimah Maryam binti Ali, Medical Laboratory Technologist. We also thanked Asst Prof Dr Muhd Firdaus Che Musa for the statistical analysis.

This study was funded by International Islamic University Malaysia (IIUM).

\section{REFERENCES}

1. Nasir S, Abu Bakar N, Samad R. Elemental and microstructural analysis of fake, real, and standard orthodontic brackets. J Phys Conf Ser 2018; 1073 (5):052002.

2. Rafeeq RA, Saleem AI, Nissan LM. Ions release from fixed orthodontic appliance in two different mouthwashes. J Baghdad Coll Dent 2014; 325 (2217):1-4.

3. House K, Sernetz F, Dymock D, Sandy JR, Ireland AJ. Corrosion of orthodontic appliances-should we care? Am J Orthod Dentofacial Orthop 2008; 133 (4):584-92.

4. Macedo de Menezes L, Cardoso Abdo Quintão C. The Release of Ions from Metallic Orthodontic Appliances. Semin Orthod 2010; 16(4):282-92.

5. Kolokitha OE, Kaklamanos EG, Papadopoulos MA. Prevalence of nickel hypersensitivity in orthodontic patients: a meta-analysis. Am J Orthod Dentofacial Orthop 2008; 134(6):722.e1-e12.

6. Basketter D, Briatico-Vangosa G, Kaestner W, Lally C, Bontinck W. Nickel, cobalt and chromium in consumer products: a role in allergic contact dermatitis? Contact dermatitis 1993; 28(1):15-25

7. Mikulewicz M, Chojnacka K, Woźniak B, Downarowicz P. Release of metal ions from orthodontic appliances: an in vitro study. Biol Trace Elem Res 2012; 146(2):272-80.

8. Wendl B, Wiltsche H, Lankmayr E, et al. Metal release profiles of orthodontic bands, brackets, and wires: an in vitro study. J Orofac Orthop 2017; 78 (6):494-503.

9. Senkutvan R, Jacob S, Charles A, et al. Evaluation of nickel ion release from various orthodontic arch wires: An in vitro study. J Int Soc Prev Community Dent 2014; 4(1):12-16.

10. Abalos C, Paúl A, Mendoza A, Solano E, Gil F. Influence of topographical features on the fluoride corrosion of Ni-Ti orthodontic archwires. J Mater Sci.: Mater Med 2011; 22(12):2813-21.

11. Kao CT, Huang TH. Variations in surface characteristics and corrosion behaviour of metal brackets and wires in different electrolyte solutions. Eur J Orthod 2010; 32(5):555-60.

12. Kuhta M, Pavlin D, Slaj M, et al. Type of archwire and level of acidity: effects on the release of metal ions from orthodontic appliances. Angle Orthod 2009; 79(1):102-10.

13. Liu C, Chu PK, Lin G, Yang D. Effects of Ti/TiN multilayer on corrosion resistance of nickeltitanium orthodontic brackets in artificial saliva. Corros Sci 2007; 49(10):3783-96.

14. Castro SM, Ponces MJ, Lopes JD, Vasconcelos M, Pollmann MC. Orthodontic wires and its corrosion-The specific case of stainless steel and beta-titanium. J Dent Sci 2015; 10(1):1-7.

15. Rerhrhaye W, Bahije L, El Mabrouk K, Zaoui F, Marzouk N. Degradation of the mechanical properties of orthodontic NiTi alloys in the oral environment: an in vitro study. Int Orthod 2014; 12 (3):271-80.

16. Yanisarapan T, Thunyakitpisal P, Chantarawaratit PO. Corrosion of metal orthodontic brackets and archwires caused by fluoride-containing products: Cytotoxicity, metal ion release and surface roughness. Orthodontic Waves 2018; 77(2):79-89.

17. Trumbo P, Yates AA, Schlicker S, Poos M. Dietary reference intakes: vitamin A, vitamin $\mathrm{K}$, arsenic, boron, chromium, copper, iodine, iron, manganese, molybdenum, nickel, silicon, vanadium, and zinc. J Acad Nutr Diet 2001; 101(3):294-301. 